\title{
CARBOHYDRATE METABOLISM IN NEPHRITIS
}

\author{
By G. C. LINDER, A. HILLER AND D. D. VAN SLYKE
}

From the Hospital of The Rockefeller Institute for Medical Research

(Received for publication, October 25, 1924)

INTRODUCTION

In an attempt to obtain further information on the incidence and significance of the hyperglycemia which has sometimes been observed in nephritis, we have studied the changes in the sugar content of the blood and urine of patients with nephritis and their respiratory metabolism following the oral administration of glucose.

That the fasting level of the blood sugar was increased in nephritis was observed by Neubauer (1) in 1910. He found that there was hyperglycemia in a large proportion of cases with very high blood pressure, and he attributed both of these conditions to excessive adrenal activity. Von Noorden (2) accepted this hypothesis, but the majority of subsequent observers rejected it, emphasizing the fact that although hyperglycemia was rarely found in nephritis without hypertension yet extreme hypertension frequently occurred without hyperglycemia. Other etiological factors were sought and its association was described with uremia, edema and dyspnea (Bing and Jakobsen, (3)), urea retention (Myers and Bailey (4)), increase in blood diastase (Myers and Killian (5)), derangement of metabolism occurring late in the disease (Williams and Humphreys (6)) and with uremia, pancreatic arterio-sclerosis or hypertension with heart failure and stasis (Kahler (7)). Härle (8) found that actual hyperglycemia was rare except in essential hypertension, but that the blood sugar was nearly always at the upper limit of normal in nephritis with increase of blood pressure. Hyperglycemia without hypertension appears to be rare, but Hopkins (9) found three instances in ten observations. The association of arterio-sclerosis, obesity and glycosuria has been recognized for many years.

The effect of glucose administration upon the blood sugar in ne- 
phritis was studied by Tachau (10) and by Bing and Jakobsen (3) who from a very few observations concluded that the effect was the same as in health. Hopkins (9), Hamman and Hirschman (11) and Bailey (12) found that the blood sugar curve was definitely abnormal when there was hypertension; the rise was exaggerated and the fall delayed. Hamman and Hirschman obtained a normal curve from a patient with edema and without raised blood pressure, and also from a case of diffuse nephritis with extreme hypertension. O'Hare (13) found definite abnormalities in 11 out of 18 cases of essential hypertension.

The kidney is relatively impermeable to glucose in some stages of nephritis (Hamman and Hirschman (11); Mason (14); Williams and Humphreys (6)). Glycosuria is often absent when the blood sugar is considerably above the normal threshold, which is now accepted as from 0.16 to 0.18 per cent $(11,15,16,17,18,19)$.

We are not aware that any observations have been made on the respiratory metabolism after glucose administration in nephritis. The object of the present work has been in part to obtain such observations in the hope that they might shed some light on the nature of the metabolic disturbance which is associated with the tendency to hyperglycemia.

\section{METHODS}

The basal metabolism determinations were made by the Tissot spirometer method (20). The Henderson modification of the Haldane gas analysis apparatus . was used (21). The protein metabolism was measured by determination of the urinary nitrogen by the Kjeldahl method. Protein when present was removed from the urine by heating and adding trichloracetic acid until no further precipitate was formed; the mixture was diluted to a volume, filtered, and the filtrate used for the nitrogen determinations. The carbohydrate metabolism was calculated from the non-protein heat production and non-protein respiratory quotient by the table given by Williams, Riche and Lusk (22).

The blood sugar determinations were made by the method of Hagedorn and Jensen (23). Foster (24) has shown that after glucose administration the sugar content of the blood obtained by finger prick is greater than that of venous blood. Folin and Berglund (19) believe that this difference is chiefly due to the greater pain and psychic effect of finger pricking, but Foster (24) sees in it evidence of the burning and storing of carbohydrate in the muscles of the arm, whence comes a large proportion of the venous blood obtained by venepuncture at the usual site. 
In observations in which changes of renal threshold may play a part, it is advisable to determine the blood sugar under conditions as nearly arterial as possible. Lundsgaard and Möller (25) found that the blood obtained by cutaneous incision is identical in oxygen content with arterial blood. We have therefore used cutaneous blood obtained by a clean deep prick with a sharp needle. Hagedorn's method has certain technical advantages, which are that $0.1 \mathrm{cc}$. of blood is all that is needed for the determination, and that the oxidizing agent is precipitated out in the reduced form as soon as reduction has occurred, reoxidation being thereby avoided.

The sugar content of the urine was tested qualitatively by the Benedict reagent and quantitatively by the Benedict and Osterberg (26) method. The albumin free filtrate prepared for the Kjeldahl determinations was used for the quantitative determinations.

Glucose ingestion tests. The subjects of these studies had been used previously by us for metabolism or else were trained by blank experiments, to accustom them to the proceedings so that psychic factors might be eliminated on the day of the test. On this day, two basal metabolism determinations over five minute periods were made after 12 to 15 hours of fasting and 30 minutes complete relaxation in bed. Blood was then taken for blood sugar determination, and urine collected. The glucose was given in $180 \mathrm{cc}$. of water and $20 \mathrm{cc}$. of lemon juice at room temperature. All times were counted from this point. Blood specimens were taken at $0.5,1,1.5,2,3$, and 4 hours, and urine specimens at 1,2 and 4 hours. Metabolism determinations were made during the five minute periods preceding the $0.5,1,2,3$, and 4 hour points.

The dose of glucose was made proportional to the normal basal requirements estimated from the height, weight (without edema), age and sex (27). The standard amount was 100 grams for an estimated normal basal rate of 1800 calories. The glucose given varied between 1.42 and 2.57 grams per kilo body weight. In some of the blood sugar determinations without metabolism determinations the dose was 100 grams for adult males, 80 to 100 grams for adult females and 55 grams for a boy, varying from 1.3 to 1.7 grams per kilo. The glucose used was Merck's "C.P."

\section{MATERIAL}

Blood sugar curves were obtained on 6 normal persons and on 12 patients with nephritis, and metabolism tests were made upon 6 normals and 7 of the patients. On 2 of the patients more than one sugar curve was obtained so that 15 curves are reported.

The blood sugar curves of the normal persons are condensed in figures 1 and 2 . Figure 1 shows those without alimentary glycosuria, and figure 2 those with alimentary glycosuria. Figures 3 to 7 show the curves obtained in the different forms and stages of nephritis, the classification being that of Volhard and Fahr (28). The shaded areas 


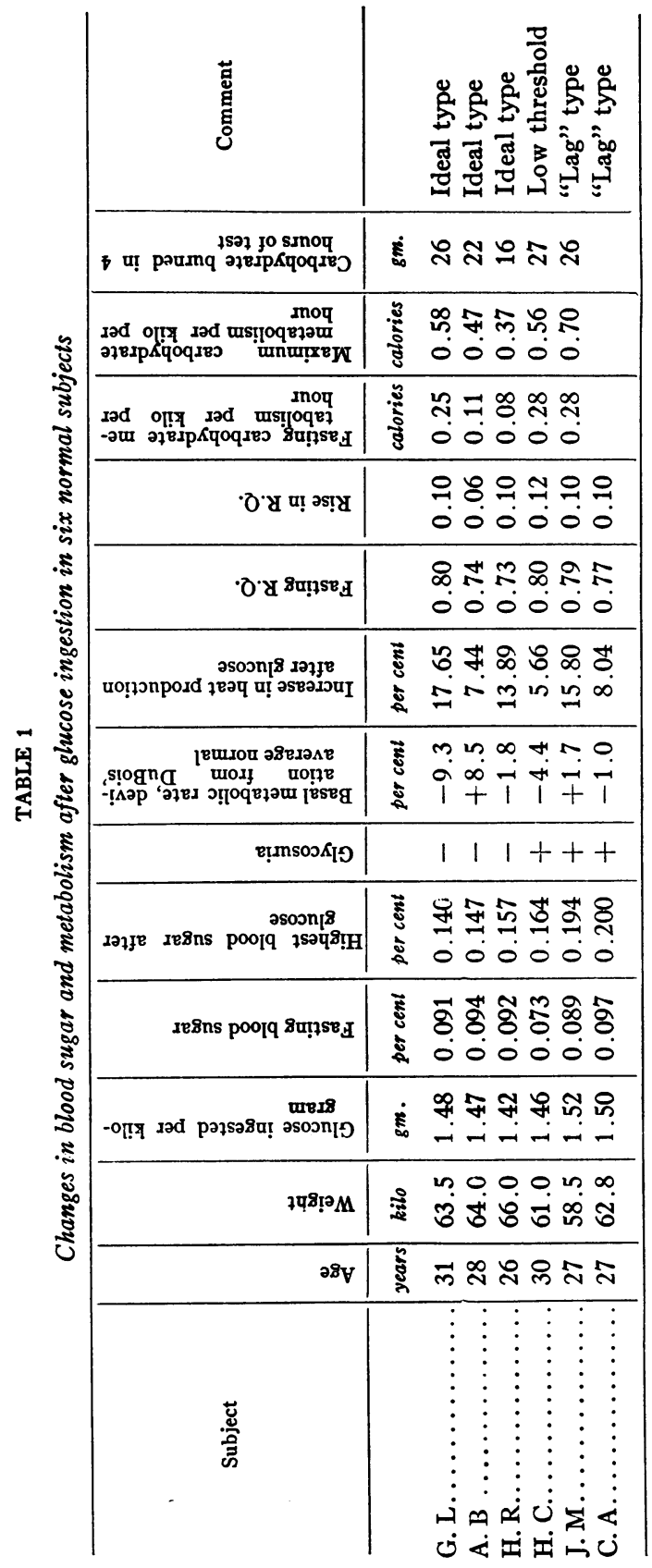


represent the zone of normal blood sugar reaction and have been drawn by taking the highest lines of figures 1 and 2, and the lowest line of figure 1.

The results of the metabolism tests are given with the corresponding blood and urine sugar determinations in figures 8 to 21 .

Tables 1 and 2 contain further facts about the tests and about the clinical condition of the patients. Protocols of the autopsy findings are appended.

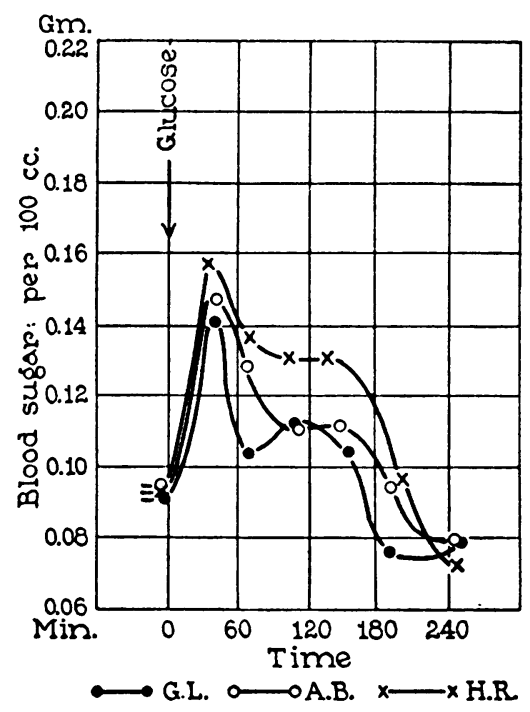

FIG. 1

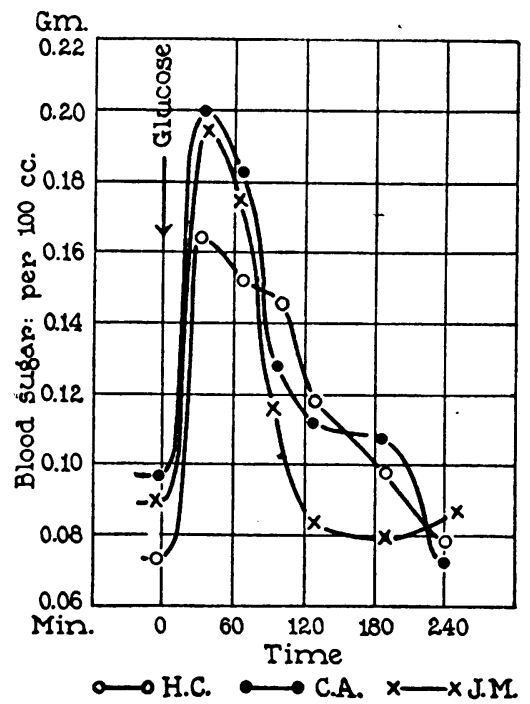

FIG. 2

Fig. 1. Blood Sugar Curves of 3 Healthy Adults in Whom There Was no GLYCOSURIA

Fig. 2. Blood Sugar Curves of 3 Healthy Adults in Whom There Was Glycosuria after Taking Glucose

The upper two curves are of the "lag" type. The glycosuria in the third case was due to a low threshold.

\section{ANALYSIS OF RESULTS \\ Normal blood sugar curves}

In order to obtain a series of controls for the observations on respiratory metabolism, glucose was given to six young healthy adult males. 
Three individuals, G. L., A. B., and H. R., (fig. 1 and table 1), presented blood sugar curves which are normal according to recent standards, and glycosuria was absent. These ideal blood sugar curves show the following points. The fasting blood sugar is less than $0.1 \mathrm{per}$ cent. After the glucose there is an abrupt rise to a peak of less than 0.18 per cent which is reached in 20 to 40 minutes. The peak is caused probably because absorption was greater at first than storage and burning. Maclean (16) suggests that this hyperglycemia is the stimulus to glycogen formation. The curve then descends steeply to a plateau 0.02 to 0.04 per cent above the fasting level and is maintained there during the second hour. During this period carbohydrate transport and storage are in equilibrium and the blood sugar comes to a constant level. When absorption and possibly the need for transport from the liver to the tissues comes to an end the curve falls to a point below the fasting level. The final hypoglycemia was observed by Frank in 1910 (29) and also by Jacobsen (15), Maclean (16), Graham (30) and Folin and Berglund (19). It is a constant phenomenon and may appear earlier if smaller doses of glucose are given.

In the remaining normal individuals, H. C., J. M. and C. A., (fig. 2 and table 1), there was sufficient sugar in the urine after the glucose to reduce the Benedict reagent. The blood sugar curves and quantitative urine sugar analyses show that two of them, J. M. and C. A., were examples of the "lag" type of curve described by Maclean (31); tardiness in starting of an otherwise normal carbohydrate storing mechanism, and possibly unusual rapidity of absorption allowed the blood sugar to rise above 0.18 per cent for a short time. Both curves showed a rapid fall to a low plateau and a terminal hypoglycemia. The threshold appeared to be normal, and the glycosuria was apparently due to the height of the peak. The urine sugar was not increased during the fasting period or after the blood sugar had fallen (figs. 12 and 13). The curve of H. C. did not show an abnormally high peak, but the fall was a little slow. The glycosuria was associated with a low threshold, probably at about 0.14 per cent (fig. 11).

Search of the literature shows that following glucose administration, glycosuria recognizable by the ordinary methods has been found in many normal subjects. Jacobsen (15) found glycosuria in 8 out of 15 persons, Hamman and Hirschman (11) in 2 out of 6, Goto and 
Kuno (32) in 33 out of 53, Hagedorn (17) frequently, and Holst (33) in 2 out of 14 healthy persons and 29 out of 145 unselected but nondiabetic patients. One of us(D.D.V.S.) when examining an army class found that 15 per cent of the members excreted small amounts of sugar after 100 grams of glucose. It is probable that some authors have not found glycosuria so often because they failed to collect a small amount of urine at the critical period; e.g., Taylor and Hulton (34) conclude that "glycosuria does not occur following the largest possible ingestions of pure glucose," but they looked for it in 24 hour collections. Other authors have refused to consider as normal persons who excrete a trace of sugar after large amounts of glucose. If that were so we should have to accept the proposition that from 15 to 50 per cent of apparently healthy people are abnormal. It appears that even when allowance has been made for age $(35,36)$, overweight (37), worry and emotion $(38,39)$, there still remains a large number of healthy people who excrete sugar after consuming considerable amounts of it.

\section{Blood sugar determinations in patients with nephritis}

Chronic nephrosis. Two curves on 2 patients (fig. 3). The sugar curve of B. B. was normal except for a small rise in the fourth hour. G. F. was 51 years old. The curve did not rise above 0.165 but in the third hour it lay above the normal limit for young persons. In neither case was there glycosuria.

Glomerulonephritis, nephrotic type, Stage II. Three curves on 2 patients (fig. 4). Two curves were within the normal area, although that of F.M. after 55 grams came to its peak in the second hour. The curve of F. M. after 74 grams, the largest dose per kilo body weight in this series, showed a delay in falling. There was no glycosuria.

Glomerulonephritis, nephrotic type, Stage III. Three curves on 3 patients (fig. 5). All the curves lay outside the normal limits. That of S. L. however, was only slightly abnormal and was similar to that of F. M. among the Stage II curves, S. L. having retained a somewhat better renal function than M. F. or S. Ly. The blood sugar of M. F. reached 0.245 per cent and although the descent was rapid, the curve was high throughout, the abnormality being definitely greater than a "lag" curve. The blood sugar of S. Ly. reached 0.227 per cent and 
TABLE 2

Observations on the blood sugar

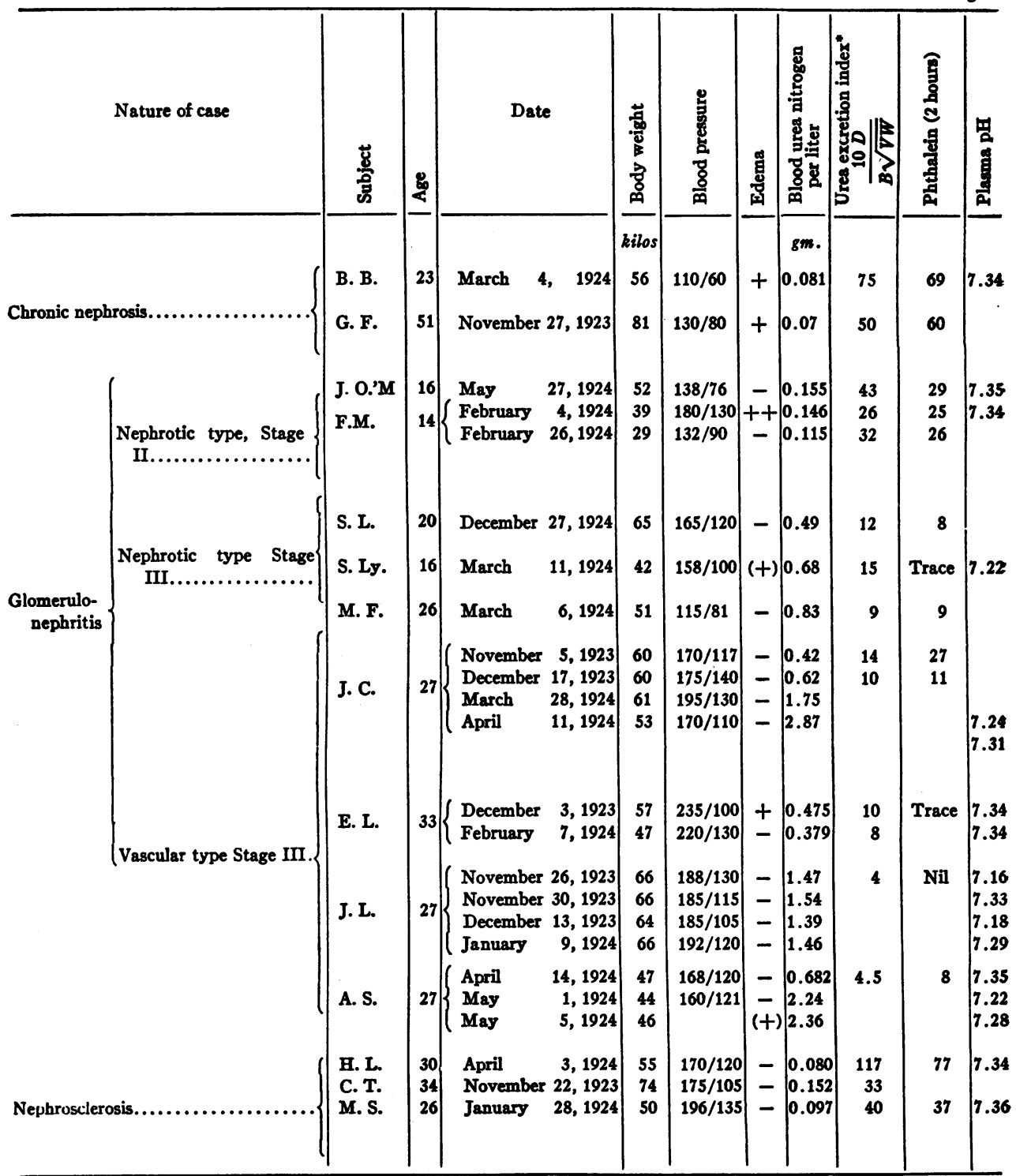

- Austin, Stillman, and Van Slyke (61). D = urea output in grams per 24 hours. B = blood ures in grams per 1. V - urine volume in 1 . per 24 hours, W. $=$ body weight in kilos. Minimum normal index $=45$.

$\uparrow$ Protocols of these patients were published in Jour. Erper. Med., 1924, rxix, 931.

t Three hours. 
and carbohydrate metabolism in nephritis

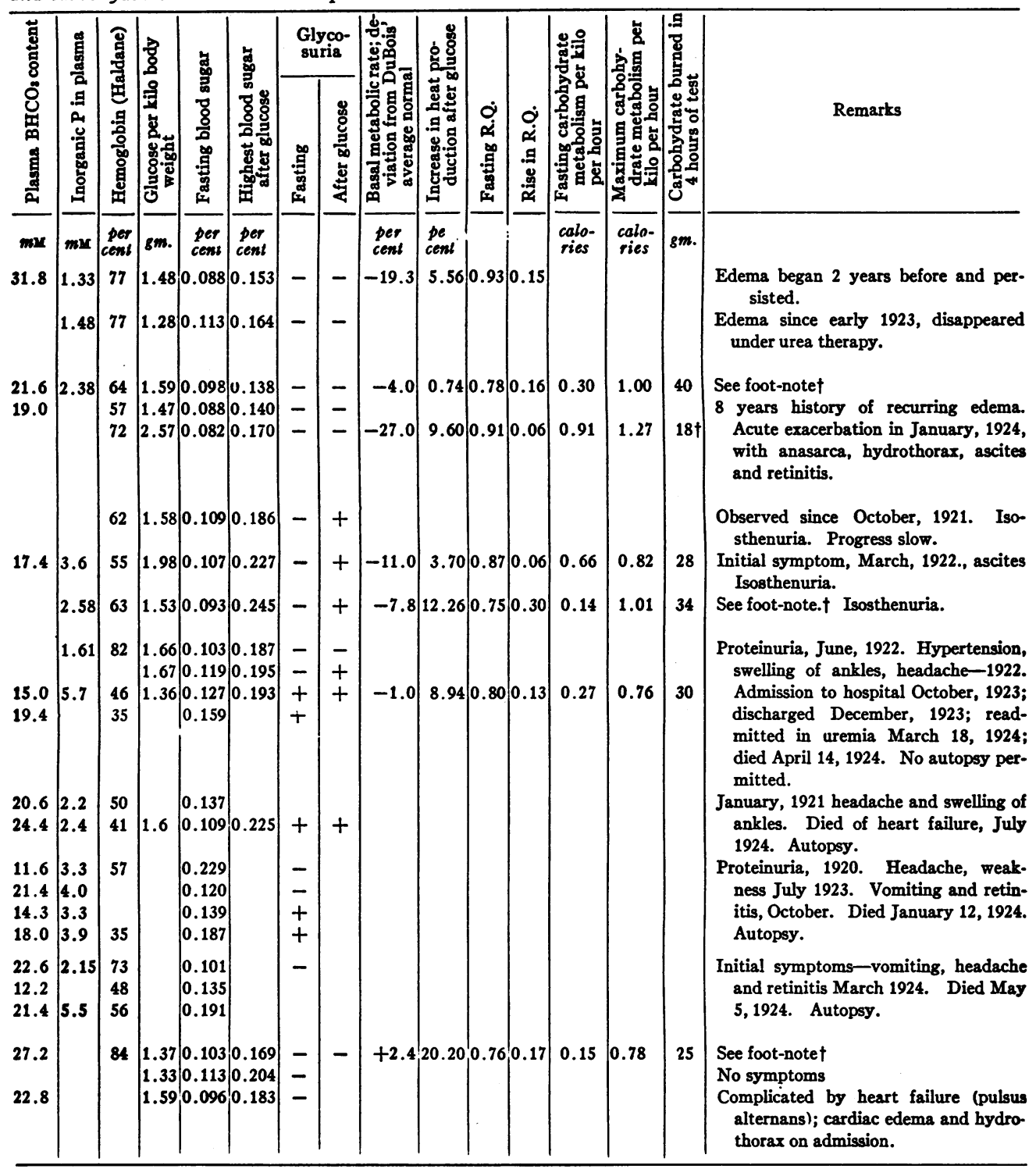


showed a yet greater delay in falling. All these patients passed traces of sugar while the blood sugar was high, but the quantity of sugar eliminated was less than would be expected from a normal person with a similar rise in blood sugar (figs. 18 and 19).

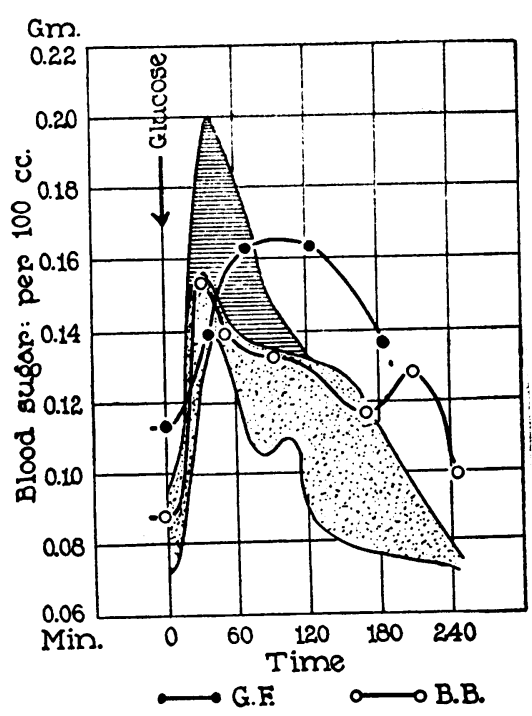

FIG. 3

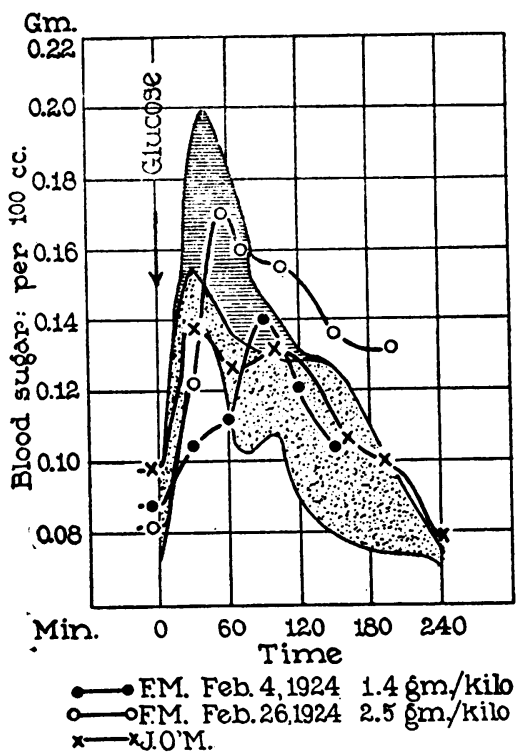

FIG. 4

Fig. 3. Blood Sugar Curves in Chronic Nephrosis

There was no glycosuria. The shaded areas in figures 3 to 7 represent the normal zone delineated from figures 1 and 2.

Fig. 4. Blood Sugar Curves in Glomerulonephrttis, Nephrotic Type, STAGE II

There was no glycosuria

Glomerulonephritis, vascular type, Stage III. Four curves on 2 patients (fig. 6). The curve of E. L. showed a high fasting level, a rise to 0.225 per cent and a steep but delayed descent. The urine habitually contained a trace of sugar which increased after the glucose was given. The threshold was low. The curves on J. C. were obtained 6 months and 5 months and 17 days before his death in uremia. The 
fasting figure rose from 0.103 to 0.119 and 0.127 per cent and 3 days before death it was 0.159 per cent (table 2). None of the tests were prolonged sufficiently to show the return of the blood sugar to the fasting level, but the fall was more and more delayed and in the last

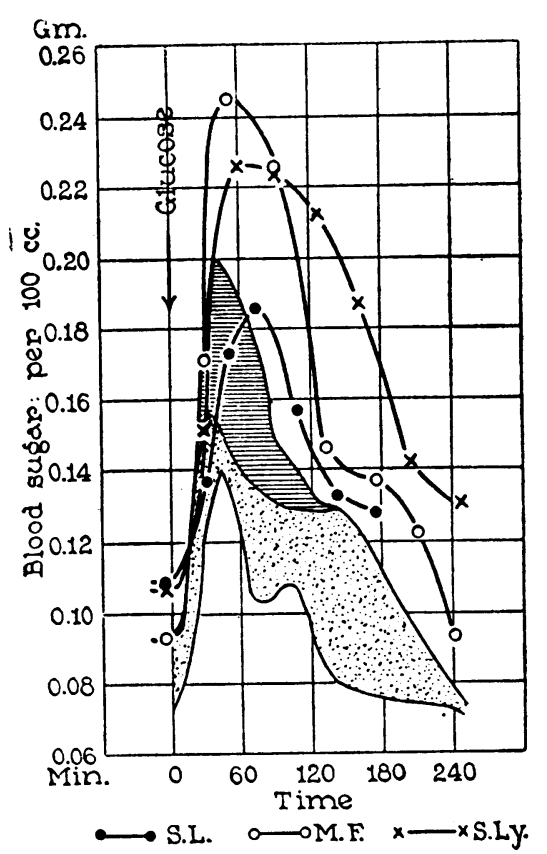

Fig. 5

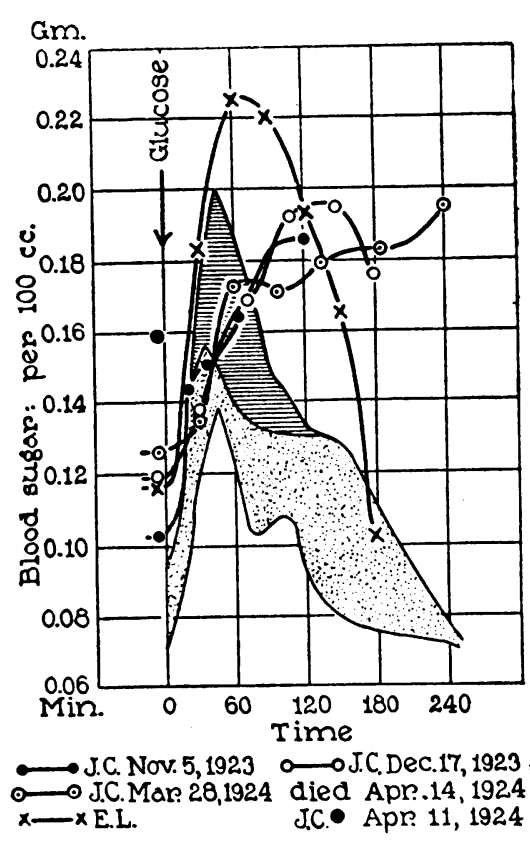

Fig. 6

Fig. 5. Blood Sugar Curves in Glomerulonephritis, Nephrotic Type, STAGE III

Glycosuria occurred in all cases

Fig. 6. Blood Sugar Curves in Glomerulonephritis, Vascular type, STAGE III

Glycosuria occurred in all tests except the earliest on J. C. There was a fasting glycosuria in E. L. and in J. C. in the third test.

curve the blood sugar was at its highest, 0.195 per cent, at the end of the fourth hour. Glycosuria was not found in the first test and only in the third hour of the second, when the blood sugar reached its maximum, the threshold at this time being therefore in the region of 0.19 per cent. In the third test there was sugar in every specimen of urine, 
including the fasting specimen, and the increased excretion after the glucose was small (fig. 20). The threshold had therefore fallen to less than 0.127 per cent. From that time he constantly excreted traces of sugar.

Table 2 contains a series of determinations of the fasting blood sugar in two other patients in this stage of nephritis, A. S. and J. L. They were too sick to allow the determination of blood sugar

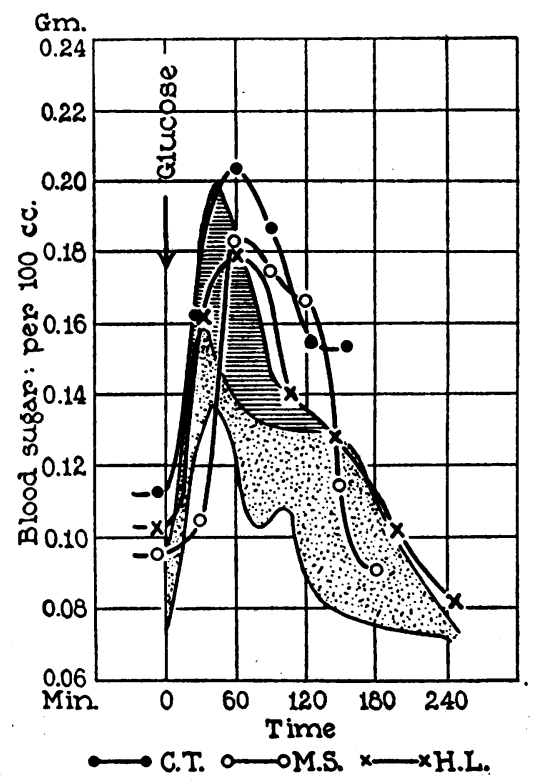

Fig. 7. Blood Sugar Curves in Nephrosclerosis, Stage I

There was no glycosuria

curves and metabolism tests, but they showed a fasting hyperglycemia which will be discussed elsewhere.

Nephrosclerosis, Stage I. Three curves on 3 patients (fig. 7). The fasting figures were normal. The curves rose high and fell more slowly than the normal curves. They extended just beyond the normal area. There was no glycosuria so that the threshold of C. T. must have been raised to about 0.20 per cent.

In chronic nephrosis and the nephrotic type of glomerulonephritis in Stage II the blood sugar curves were substantially normal in form 
and in no case was there glycosuria. In nephrosclerosis with little or no renal insufficiency the curves were all of a slightly exaggerated "lag" type, and the fasting blood sugar was towards the upperlimit of normal. In both varieties of glomerulonephritis in Stage III with renal insufficiency the curves were, with one exception, S. L., definitely abnormal with exaggerated rise and delayed fall, and glycosuria was frequently present. A fasting hyperglycemia was observed in the last days of life.

The abnormalities in the blood sugar curves could not be attributed in these cases to a lowered basal metabolic rate, as in the cases described by Hoxie (40). He reported that subjects with a basal metabolic rate below -10 per cent show sugar tolerance curves of the diabetic type. Although we have frequently found the basal metabolic rate lowered in nephritis, the two patients reported here with a lowered metabolic rate, B. B. and F. M., table 2, did not present essential abnormalities in their blood sugar curves, while J. C., who had a normal basal metabolic rate, presented the most extreme type of curve.

\section{Carbohydrate metabolism of normal subjects}

After the glucose was taken the respiratory quotient rose 0.06 to 0.12 above the basal level, and it remained at a raised figure until the fourth hour (figs. 8 to 13 and table 1). In no instance did this rise begin until the second half of the first hour. This delay after glucose is given by mouth is characteristic, and was observed by Benedict (41) Zuntz and Mering (42), Bernstein and Falta (43) and Sanger and Hun (44). Bernstein and Falta believe that the glucose is first stored as glycogen, and only when the glycogen depots are filled is it burned or converted into fat causing the respiratory quotient to rise. The type of curve obtained would thus depend upon the state of the glycogen depots, and this in turn upon the preceding diet. Higgins (45) and Bornstein and Holm (46) found that the quotient actually fell during the first 15 minutes. The latter authors suggested that this was due to $\mathrm{CO}_{2}$ being retained in the body to combine with the alkali released by secretion of acid in the gastric juice, as Bennett and Dodds (47) had found that the alveolar $\mathrm{CO}_{2}$ was increased at 
that time. Such retention would result in a fall of quotient which would mask any rise due to increased carbohydrate metabolism.

A definite increase in heat production was present in half an hour and reached its maximum then in 2 cases, G. L. (fig. 8) and C. A., (figure 13); in the remaining 4 cases the maximum was delayed until one hour or later when the blood sugar curve was falling. The heat production curves of Sanger and Hun (44) were of similar form. Our curves returned to the basal level in 2 to 3 hours.

The carbohydrate combustion was less than 0.3 calories per kilo per hour during the fasting period, and it did not rise until the second half hour. The maximum combustion was attained in the second or third hour and varied from 0.37 to 0.7 calories. In the fourth hour there was a fall. In G. L. this fall was to 0.07 calories, and in H. R. to 0.03 ; in these subjects there was well marked hypoglycemia at this time, but hypoglycemia occurred in A. B., H. C., and J. M. without an excessive fall in carbohydrate combustion within the 4 hours of the test. The amount of sugar burned in the 4 hours of the test varied from 16 to 27 grams.

It appears that the accelerated metabolism of carbohydrate plethora (48) begins as soon as the blood and tisssues are flooded with sugar, but that the increase in respiratory quotient occurs a little later.

Figure 14 shows the effect of $200 \mathrm{cc}$. of water alone on the metabolism of the subject G. L. The respiratory quotient fell and the carbohydrate combustion calculated from the gas exchange reached a low

\section{Explanation of figures 8 to 21}

The abscissae represent the time in minutes before and after the glucose was given at "zero." The ordinates have three scales. The outer scale on the left side gives the total metabolism and carbohydrate metabolism in calories per kilo per hour, and the respiratory quotient. The inner scale gives the blood sugar in grams per $100 \mathrm{cc}$. The scale on the right hand side gives the rate of sugar excretion in grams per hour.

The following signs indicate the curves.

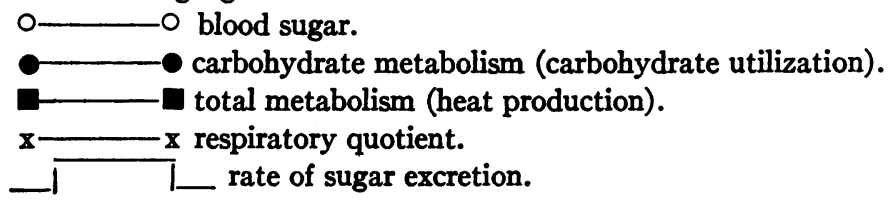




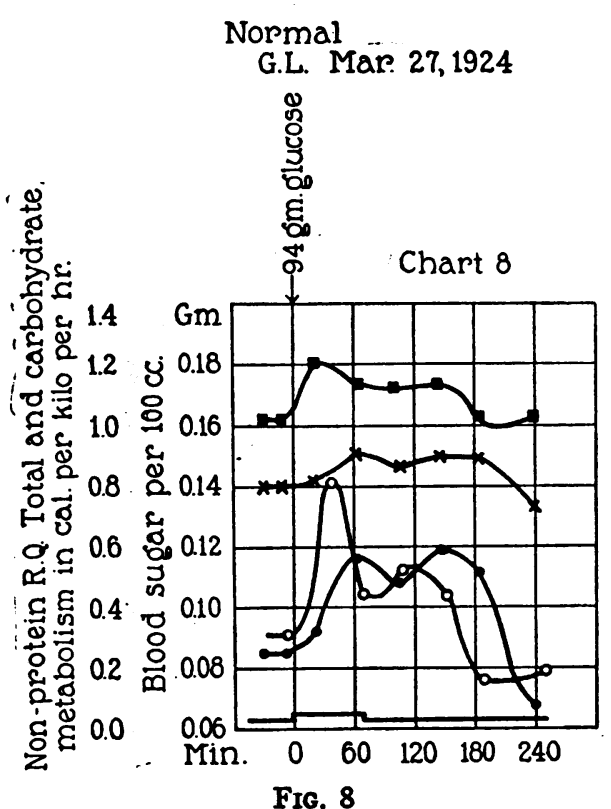

Normal

H.R. June 10, 1924

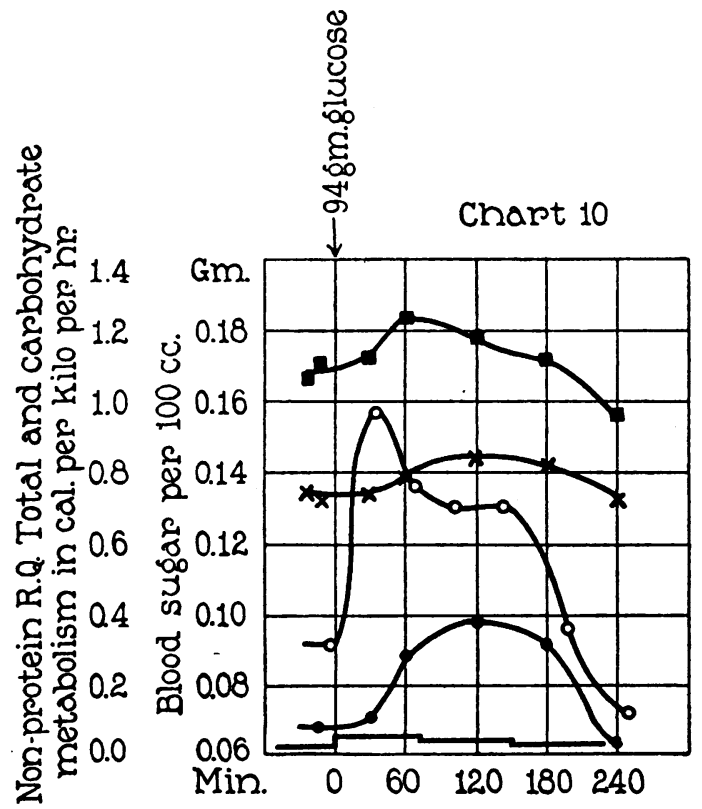

Fig. 10
Normal

A.B. Apr 1. 1924

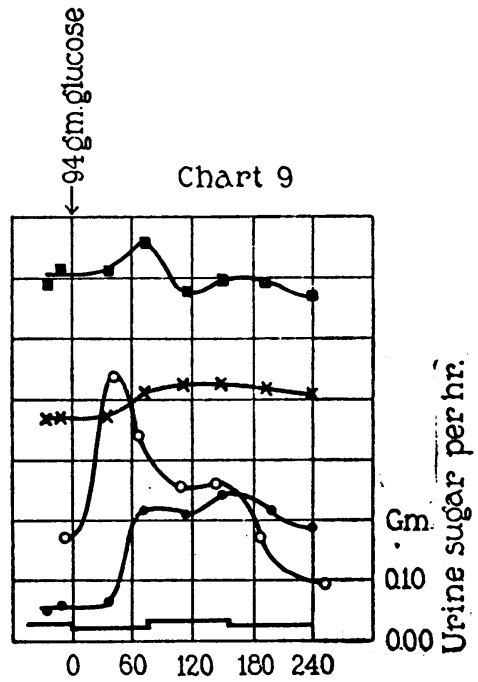

Fig. 9

Normal

H.C. June 11. 1924

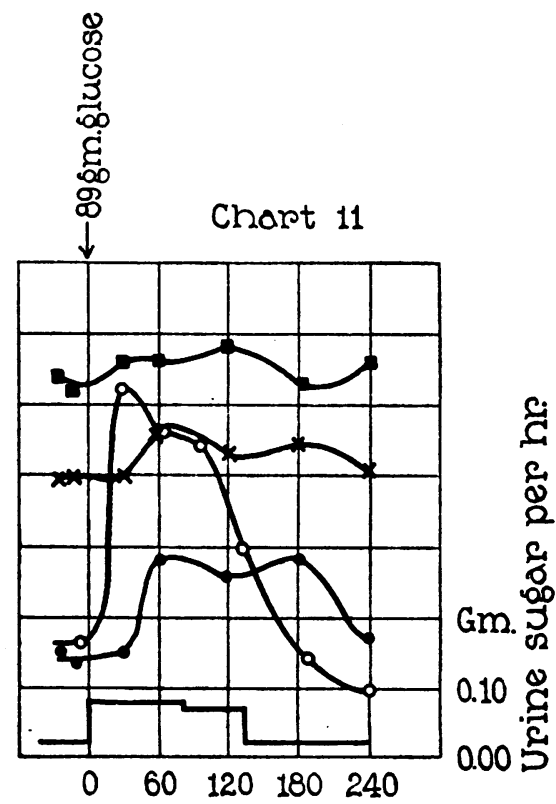

Fig. 11 
Normal

J.M. June 3, 1924

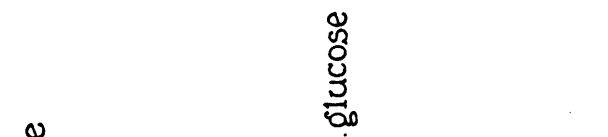

$\frac{0}{0}$

这

융 1.4

ชิ 1.2

ช

덩 1.0 으 0.16

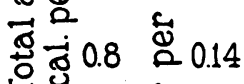

$\sigma .50 .6$ क्ष 0.12

ल

с है 0.4

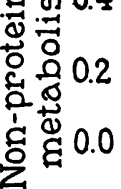

ज. 0.10

음 0.08

0

0.06 M.in.

Chart 12

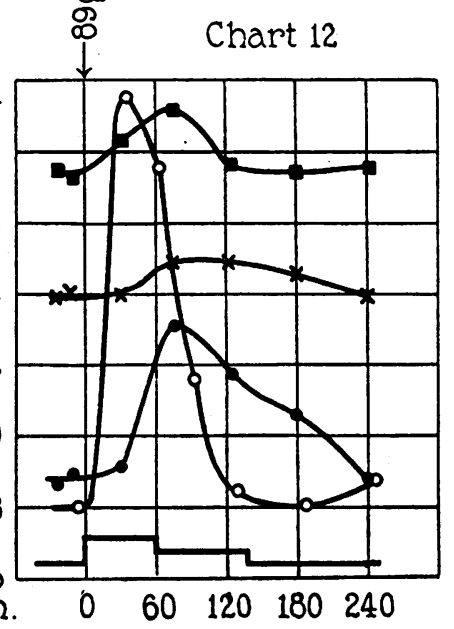

Fig. 12

Control test, normal

G.L. May 8.1924

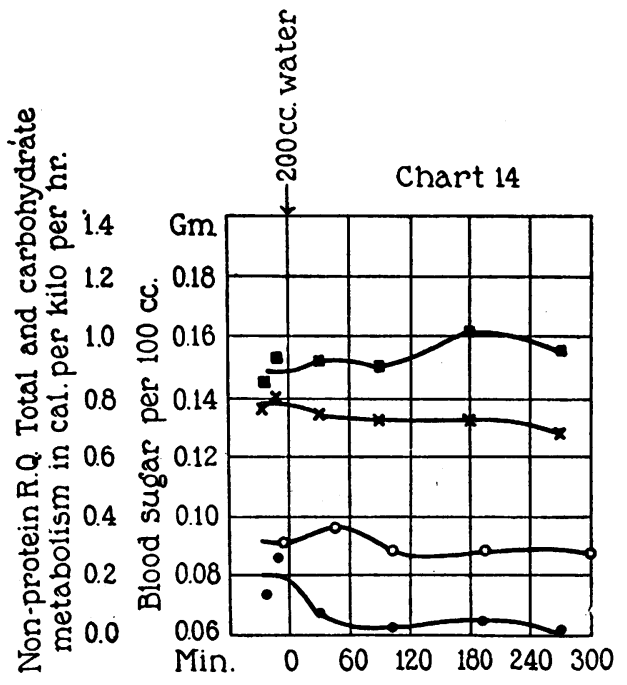

Fic. 14
Normal

C.A. June 12, 1924
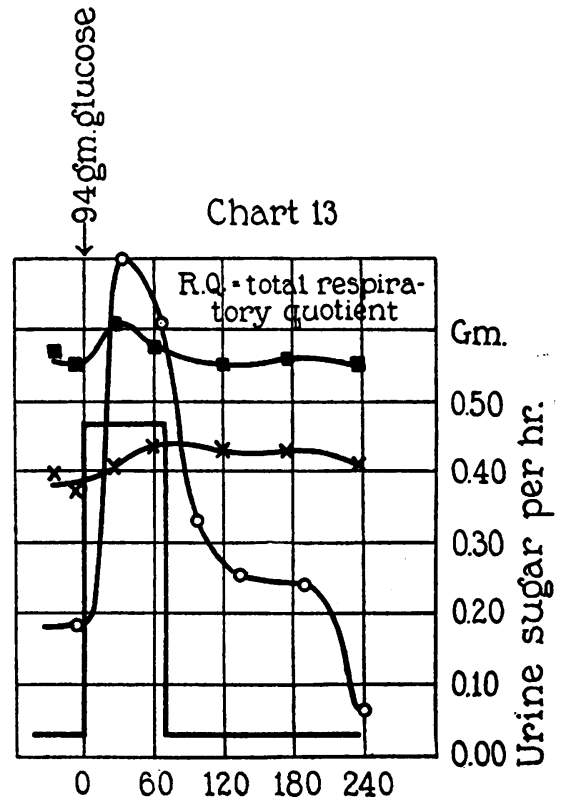

Fig. 13

Chronic nephrosis

B.B. Mar. 4, 1924

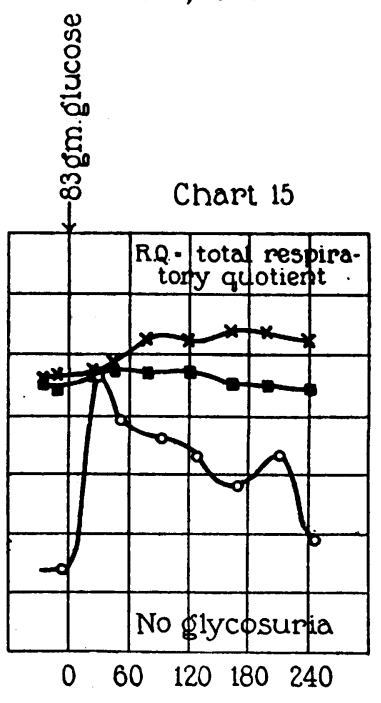

Fig. 15 


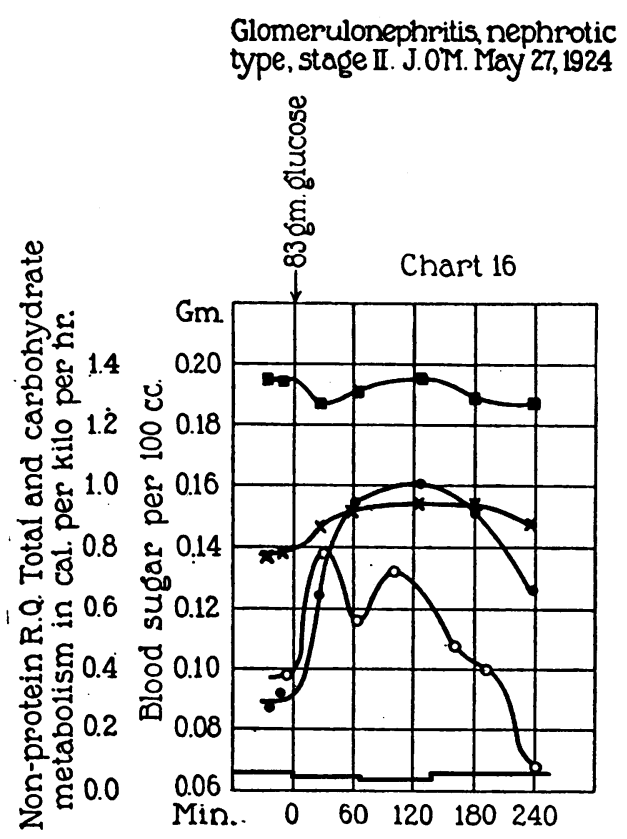

Fig. 16

Glomerulonephritis, nephrotic type, stage III. M.F. Mar 6, 1924

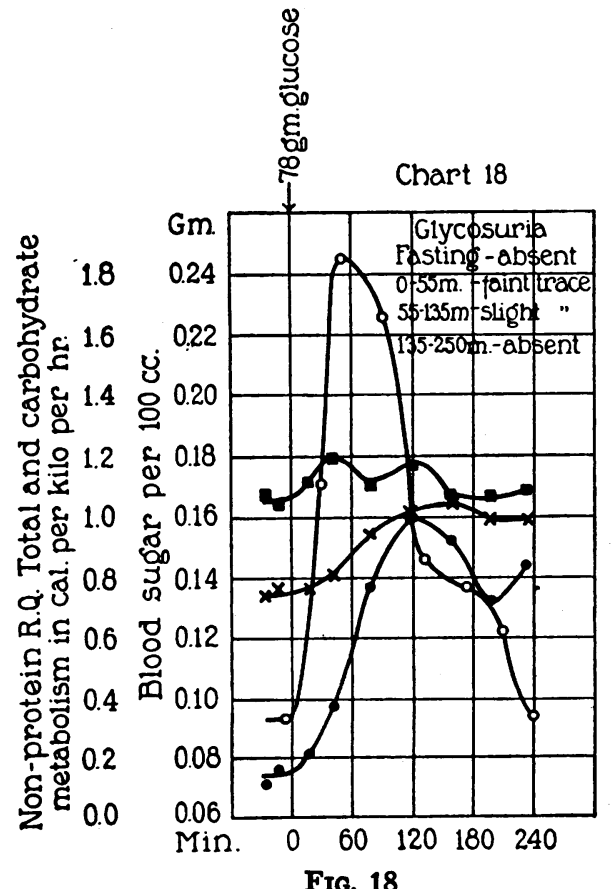

Glomerulonephritis, nephrotic type, stage I, F.M. Feb. 26.1924

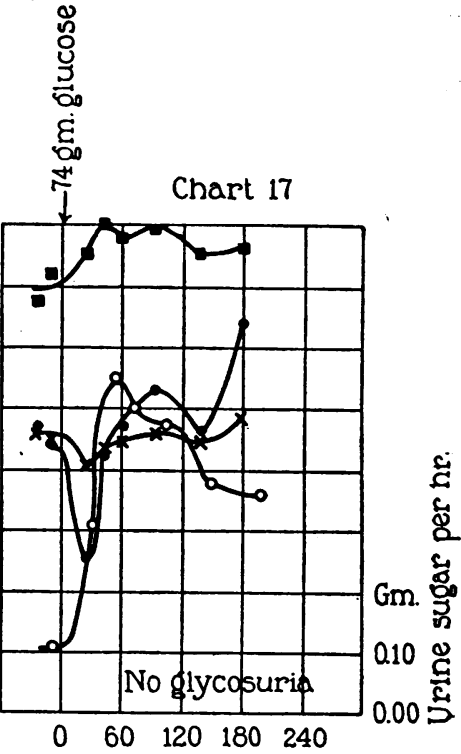

Fig. 17

Glomerulonephritis, nephrotic type. stage III. S.Ly. Mar.11, 1924

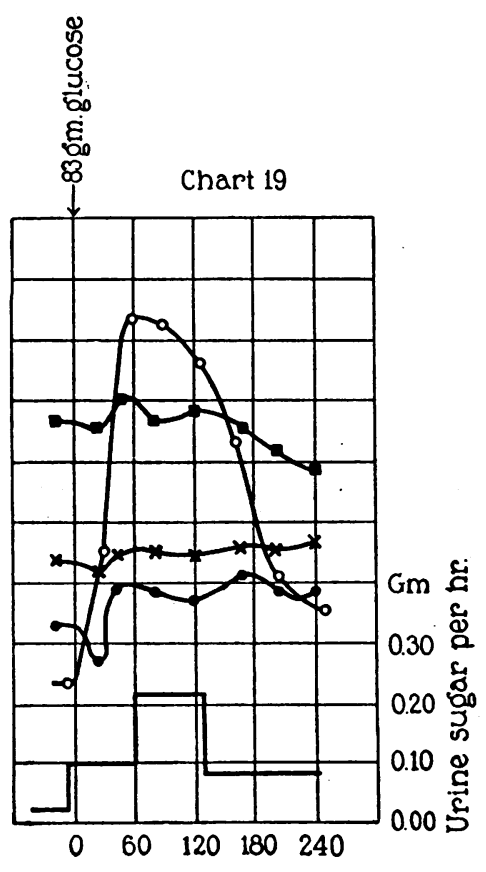

Fic. 19 
level. There was no significant change in the blood sugar; there was no hypoglycemia within 5 hours, that is, after 20 hours fasting. There was no effect on the basal heat production.

\section{Carbohydrate metabolism of patients with nephritis}

Chronic nephrosis. Case B.B. (figure 15). Glomerulonephritis, nephrotic type, Stage II. Cases J. O'M. and F. M., (figs 16 and 17). B. B. showed a rise in respiratory quotient above unity and a normal

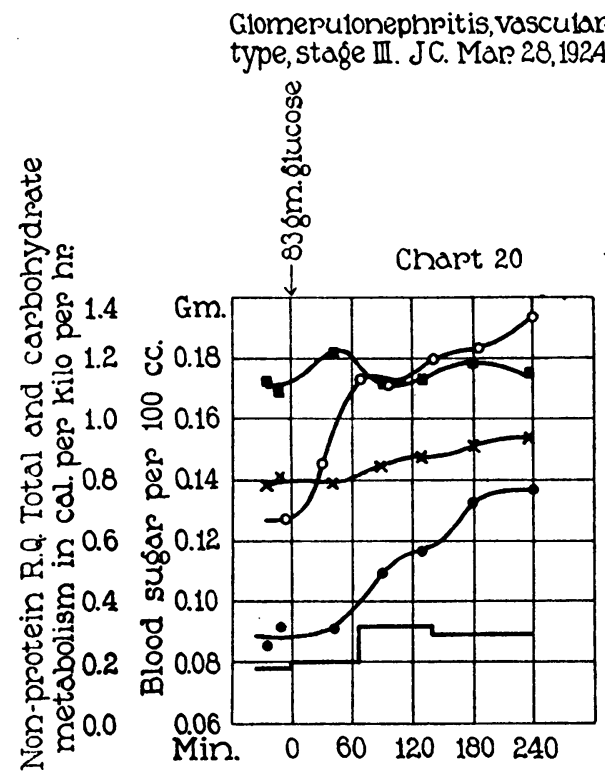

Fig. 20
Nephrosclerosis, stage I.
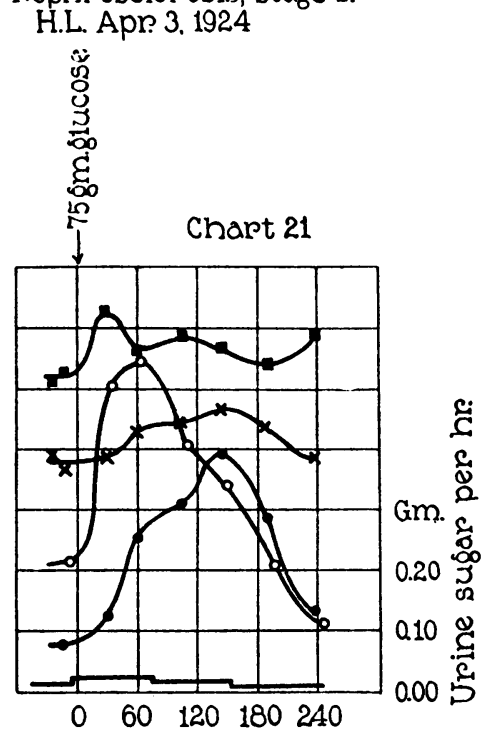

Fig. 21

increase in heat production. He was being treated with urea so that his protein metabolism could not be determined, and his carbohydrate combustion could not be calculated. The height of the quotient showed that the carbohydrate was actively utilized and that some of it was converted into fat. The carbohydrate burned by J. O'M. before the glucose was given was 0.3 calories per kilo per hour, while immediately after the glucose it increased with a rise of respiratory quotient and reached 1 calorie. During the test he burned 40 grams of glucose. F. M. showed an increase in heat production which re- 
mained above the basal level until the end of the test. There was a striking transient fall of the respiratory quotient after 25 minutes and it did not rise above the initial level until the third hour. Carbrohydra te combustion was 0.9 calories in the fasting state, and except for a fall at the $\mathbf{2 5}$ minute period it remained at a high level. The test was discontinued after 3 hours, during which time 18 grams of sugar were burned.

Glomerulonephritis, Stage III. Cases M. F., S. Ly., J. C. (figs. 18 to 20). The blood sugar curves of these patients were definitely abnormal. The heat production of M. F. rose immediately and returned to the basal level in the third hour. The respiratory quotient rose from 0.75 to 1.05 . The carbohydrate combustion was 0.15 calories before the glucose, began to increase immediately after, and reached 0.98 calories at the end of the second hour. Thirty grams of carbohydrate were burned during the test. As in B.B. the rise of the respiratory quotient above unity indicated that some of the glucose was converted into fat. Both of these patients had permanent lipemia. S. Ly. showed but slight increases in heat production and respiratory quotient. The utilization was high in the fasting condition , 0.66 calories. It fell with the respiratory quotient at the $\frac{1}{2}$ hour point and then rose moderately to 0.75 calories where it remained to the end of the test. Twenty-eight grams of sugar were burned. The apparent lack of response was due to the initial high level of carbohydrate metabolism. The heat production of ' J. C. increased during the first hour, but there was no change in the respiratory quotient and carbohydrate metabolism, the latter remaining at 0.3 calories. After the first hour the quotient and carbohydrate metabolism rose steadily until the end of the test, the curves running parallel with that of the blood sugar. The carbohydrate combustion reached a maximum of 0.76 calories at the end of the fourth hour, thirty grams of carbohydrate being burned in the 4 hours. The curves suggested that absorption was slow and that the increase of carbohydrate metabolism in response to carbohydrate plethora was sluggish but eventually attained normal proportions.

Nephrosclerosis. Case H. L. (fig. 21). All the metabolism curves were of normal form. The carbohydrate combustion rose from 0.15 to 0.78 calorie per kilo per hour and 25 grams of sugar were burned during the period of observation. 
There was no constant characteristic difference between the respiratory quotients of normal persons and those of patients with nephritis after glucose administration, whether or not there were abnormal blood sugar curves. The results indicate that after glucose ingestion a somewhat more rapid carbohydrate combustion occurred in some of the nephritic patients than in the normal subjects. The differences, however, are not sufficiently marked, in view of the small number of cases, to permit a decision as to whether they are significant of the disease or are merely such variations as might be caused by previous diet and individual variation in normal subjects.

\section{DISCUSSION}

In the interpretation of glycosuria and supposedly pathological conditions of the blood sugar it is essential to allow for physiological variations. Spence (35) and Punschel (36) have shown that in later life alimentary hyperglycemia is prolonged, and the former has suggested that the abnormalities reported in nephritis are nothing but the normal response in the elderly. Many of the published curves, particularly those in cases of hypertension, are difficult to evaluate for this reason. Our series includes one patient of 51 years, but the remainder are under 35 , so that the effect of old age has been eliminated. None of our patients were pregnant or menstruating, and none had had any recent acute infection, or any gross cerebral vascular lesion. Graham (37) found that his blood sugar curve was considerably higher when he was hard at work than just after he returned from a holiday, and this factor may apply to the normals C. A. and J. M. as they would possibly present "ideal" curves after a vacation. We have called no case abnormal unless there was a gross departure from the normal behavior of the blood sugar or carbohydrate utilization which could not be explained by some physiological condition.

Definitely abnormal blood sugar curves were obtained in Stage III of glomerulonephritis-the stage of marked nitrogen retention and isosthenuria.

The existence or not of very high blood pressure appeared to be immaterial, as S. Ly. and M. F. with blood pressures of $158 / 100$ 
and $115 / 81$ showed grossly abnormal sugar curves, although the fasting blood sugar was normal. (We have not observed these nephrotic cases in the days just preceding death from uremia. In nephrosclerosis, or essential hypertension, in young persons the curves were of a slightly exaggerated "lag" type. Hypertension is not related to hyperglycemia in any constant way.

In the cases with renal edema there was no abnormality of the blood sugar.

The abnormal blood sugar curves were found in conditions of severe renal insufficiency in association with a low urea excretion index, accompanied in most cases by acidosis and phosphate retention. Cammidge (50) believes that variations in blood sugar after food are due to digestive changes in the acid-base balance of the blood, and Langfeldt (51) has demonstrated that decreasing the $\mathrm{pH}$ to 6.8 increases the rate of glycogenolysis by liver diastase to a maximum and advances the hypothesis that change in $\mathrm{pH}$ in the liver cells is one important factor in regulating the level of the blood sugar. Table 2 shows that, of the patients for whom acid-base determinations are available, all those with normal blood sugar curves had a normal acid-base balance, and all but one, E. L., of those with abnormal sugar curves had some degree of uncompensated acidosis. However, the correlation of the height of the fasting blood sugar with the degree of acid-base disturbance in the same patient is imperfect. In the case J. C. the $\mathrm{pH}$ and $\mathrm{BHCO}_{3}$ were more nearly normal when the fasting blood sugar was 0.159 per cent than when it was 0.127 per cent. In J. L. there was a blood sugar of 0.229 per cent and severe acidosis, and four days later after bicarbonate therapy both states were almost normal; later when the acidosis approached the initial degree the blood sugar rose to 0.139 per cent and finally with an improvement in the acidosis the sugar increased to 0.187 per cent. In the case of $A$. S. there was the same discrepancy. The conclusion that acidosis is the cause of the abnormal blood sugar curves does not seem justified by our data, although they are not complete enough to exclude blood reaction as a possible factor in sugar metabolism.

That phosphates take part in the carbohydrate metabolism, presumably by combining with glucose or some of the intermediate 
compounds has been shown by Embden, whose work has been reviewed by Shaffer (52) and supported by the results of Harrop and Benedict (53). Renal insufficiency is likely to be accompanied by phosphate retention, as shown by Marriott and Howland (54) and by our results. If increased blood phosphate had any effect on glucose utilization, however, an acceleration rather than a retardation would be expected. Our results indicate no relationship between phosphate retention and altered carbohydrate metabolism in nephritis, except as two results of the same disease.

In the same way urea retention occurred with the abnormalities in blood sugar but no close relation was apparent.

In another communication (55) we report observations on substances in normal blood other than glucose which reduced the ordinary blood sugar reagents and find that these substances are increased in uremia. This increase, however, accounts for but a small fraction of the apparent hyperglycemia, the larger fraction being due to an increase in fermentable sugar.

The question, whether the corpuscles normally contain sugar in man or not, remains a matter of dispute. Of recent workers Falta and Richter-Quittner (56), Brinkman and Davis (57), and Csáki (58) found that human corpuscles contained no sugar, but Hagedorn (59), Ege (60) and Folin and Berglund (19) found that they contained a considerable amount. If it were assumed with some of these authors $(56,57,58)$ that all the blood sugar is in the plasma, most of the high values observed in our nephritic cases could be explained as due to a relative increase in the plasma: cell volume ratio. The abnormally long persistance of high blood sugar after glucose ingestion could not be so explained, and in view particularly of the analyses of Folin and Berglund (19) one cannot lay much weight on the assumption of sugar-free corpuscles.

No change in the threshold for sugar was demonstrated in the majority of the patients until the terminal stage of the disease was reached. Of the three patients with nephrosclerosis none showed glycosuria, but in one of them the blood sugar rose to 0.203 per cent and in another to 0.183 per cent, the threshold being raised in the former and probably in the latter. Towards the end of Stage III of glomerulonephritis the threshold fell to a low figure and a fasting 
glycosuria appeared in three of the four fatal cases. In the fourth an adequate search was omitted. The threshold fell to the region of 0.13 per cent. The quantity of sugar excreted was small, however, even when the blood sugar rose to 0.22 and 0.24 per cent. Although the blood concentration level at which sugar escaped in the urine might be lowered, the excretion rate appeared to be retarded so that the amount lost was less than would be excreted by normal persons with an equal degree of hyperglycemia. (See figures 13, 18, 19 and 20.)

\section{SUMMARY}

In glomerulonephritis with severe renal insufficiency (Stage III) the blood sugar curves after glucose was given by mouth showed an exaggerated and prolonged rise, and glycosuria occurred. In the terminal stage hyperglycemia and glycosuria were present in the fasting state, the threshold for sugar being reduced.

In glomerulonephritis without severe renal insufficiency (Stage II) and in chronic nephrosis no substantial abnormality of the blood sugar was found either during fasting or after glucose feeding.

In nephrosclerosis with little or no renal insufficiency the fasting blood sugar was close to the upper limit of normal, and the rise after glucose was slightly higher and more prolonged than normal. The threshold appeared to be raised.

The rate of increase in the respiratory quotient after glucose ingestion indicated that combustion of carbohydrate was as rapid in the patients of all types as in normal subjects. The delay in the fall to normal blood sugar levels after glucose ingestion, noted in nephrosclerosis and severe glomerulonephritis, is attributable to some factor, such as retarded glycogen formation, other than failure to burn the sugar.

\section{AUTOPSY REPORT}

E. L. Moderate peripheral edema. Hydrothorax, about 1 liter. Heart: 555 grams. Hypertrophied and dilated; no valvular insufficiency; slight coronary atheroma. Kidneys: Right 80 grams, left 70 grams. The capsule stripped with difficulty exposing a very finely granular grayish-yellow surface. On section the differentiation of cortex and medulla was obscure, and the cortex narrow. In the left kidney there was the scar of a large infarct. 
Histology. In many areas the glomeruli were reduced to hyaline scars. A few glomeruli were of large size, showed an increase of nuclei and relative blood lessness. Most of the remainder showed epithelial crescents, hyaline and fatty changes in the tufts, adhesions and fibrous thickening of the capsule. Many tubules had disappeared, and there were fatty changes in the epithelium of the remainder. There was a great increase of the interstitial tissue and in places infiltration with small round cells. The medium vessels showed hypertrophy of the media and intima, and the smallest vessels hyperplastic intimal sclerosis.

Diffuse hyperplastic intimal sclerosis was found in the pancreas, spleen and uterus.

J. L. Fluid in both pleural and in peritoneal sacs. Heart: 490 grams. Valves intact; the muscle light brown and firm. Kidneys: The left weighed 95 grams. The capsule was slightly adherent, the surface very pale and slightly granular. The differentiation of cortex and medulla was obscure. The cortical markings were indistinct and the whole cut surface appeared pale, gelatinous and homogeneous. The right kidney weighed 35 grams. There was a malformation of the pelvis, otherwise it was similar to the left.

Histology. Large groups of glomeruli were reduced to hyaline and fibrous scars. In others there was epithelial proliferation, crescent formation and adhesions. In some the capsule was greatly thickened by concentric layers of fibrous tissue. A few were comparatively well preserved but showed hyaline degeneration of the tufts. All the glomeruli appeared bloodless. Many tubules had disappeared, and the remainder were dilated and lined with flattened or cubical cells. The arteries of medium size were greatly thickened and a few of the smallest showed hyperplastic intimal sclerosis. There was a diffuse interstitial infiltration with connective tissue and small round cells, although a few islands containing the remaining tubules and glomeruli had escaped this infiltration to some extent.

Diffuse hyperplastic sclerosis was present in the kidney and pancreas.

A. S. Weight 45 kilos. No fluid in chest or abdomen. Heart: 330 gram s. Mitral and aortic valves slightly thickened but not incompetent. Kidneys: 90 grams each. The capsule stripped with great difficulty, leaving a pale, finely nodular surface. On section the cortex was very much reduced and the small arteries stood out prominently.

Histology. Many glomeruli had disappeared and the remainder showed either hyaline degeneration or proliferation of the epithelial cells of the tufts and capsules, only a very few having escaped. There were numerous large "crescents." The glomeruli contained little blood. The tubules were dilated and the epithelium flattened. The coats of the medium and larger arteries were greatly thickened and the elastic lamina split into two or more layers. The smallest arteries showed hyperplastic intimal sclerosis with fatty degeneration. There was a diffuse increase of fibrous tissue in the interstitial spaces and localized areas of infiltration with small round cells. 
Diffuse hyperplastic sclerosis was found in the kidneys, spleen, pancreas and liver.

\section{BIBLIOGRAPHY}

1. Neubauer, E. Biochem. Zeitscht., 1910, xxv, 284.

2. Von Noorden, C. Die Zuckerkrankheit und ihre Behandlung, Berlin, 1917.

3. Bing, H. J., and Jakobsen, B. Deutsch. Arch. f. klin. Med., 1914, cxiii, 571.

4. Myers, V. C., and Bailey, C. V. Jour. Biol. Chem., 1916, xxiv, 147.

5. Myers, V. C., and Killian, J. A. Jour. Biol. Chem., 1917, xxix, 179.

6. Williams, J. R., and Humphreys, E. M. Arch. Int. Med., 1919, xxiii, 537.

7. Kahler, H. Wien, Arch. f. klin. Med., 1922, iv, 129.

8. Härle, F. Zeitscht. f. klin. Med., 1921, xcii, 124.

9. Hopkins, A. H. Amer. Jour. Med. Sci., 1915, cxlix, 254.

10. Tachau, H. Deutsch. Arch. f. klin. Med., 1911, civ, 437.

11. Hamman, L., and Hirschman, I. Arch. Int. Med., 1917, xx, 761.

12. Bailey, C. V. Arch. Int. Med., 1919, xxiii, 455.

13. O'Hare, J. P. Amer. Jour. Med. Sci., 1920, clx, 366.

14. Mason, E. H. Arch. Int. Med., 1918, xxi, 216.

15. Jacobsen, A. Th. B. Biochem. Zeitscht. 1913, lvi, 471.

16. Maclean, H., and de Wesselow, O. L. V. Quart. Jour. Med., 1920-21, xiv, 103.

17. Hagedorn, H. C. Acta Med. Scand., 1920, liii, 672.

18. Graham, G. Pathology and Treatment of Diabetes Mellitus, London, 1923, p. 58.

19. Folin, O., and Berglund, H. Jour. Biol. Chem., 1922, li, 213.

20. Boothby, W. M., and Sandiford, I. Basal Metabolic Rate Determinations, Philadelphia, 1920.

Carpenter, T. M. A Comparison of Methods for Determining the Respiratory Exchange of Man, Carnegie Institute of Washington, 1915, Publication No. 216, p. 61.

21. Henderson, Y. Jour. Biol. Chem., 1918, xxxiii, 31.

22. Williams, H. B., Riche, J. A., and Lusk, G. Jour. Biol. Chem., 1912, xii, 349.

23. Hagedorn, H. C., and Jensen, B. N. Biochem. Zeitscht. 1923, cxxxv, 46.

24. Foster, G. Jour. Biol. Chem., 1923, lv, 291.

25. Lundsgaard, C., and Möller, E. Jour. Exp. Med., 1922, xxxvi, 559.

26. Benedict, S. R., and Osterberg, E. Jour. Biol. Chem., 1921, xlviii, 51.

27. Aub, J. C., and DuBois, E. F. Arch. Int. Med., 1917, xix, 823.

28. Volhard, F., and Fahr, T. Die Brightsche Nierenkrankheit, Berlin, 1914.

Volhard, F. Die doppelseitigen hämatogenen Nierenerkrankungen, Berlin, 1918.

29. Frank, E. Zeitscht. f. physiol. chem., 1910-11, lxx, 291.

30. Graham, G. Pathology and Treatment of Diabetes Mellitus, London, 1923, p. 32 . 
31. Maclean, H. Modern Methods in Diagnosis and Treatment of Glycosuria and Diabetes, London, 1922, p. 42.

32. Goto, K., and Kuno, N. Arch. Int. Med., 1921, xxvii, 224.

33. Holst, J. E. Zeitscht. f. klin. Med., 1922, xcv, 394.

34. Taylor, A. E., and Hulton, F. Jour. Biol. Chem., 1916, xxv, 173.

35. Spence, J. C. Quart. Jour. Med., 1920-21, xiv, 314.

36. Punschel, A. Zeitscht. f. klin. Med., 1923, xcvi, 253.

37. Graham, G. Jour. Physiol., 1915-16, 1, 285.

38. Folin, O., Denis, W., and Smillie, W. G. Jour Biol. Chem., 1914, xvii, 519.

39. Macleod, J. J. R. Physiology and Biochemistry in Modern Medicine, St. Louis, 1918, p. 674.

40. Hoxie, G. H. Jour. Lab. Clin. Med., 1922-23, viii, 112.

41. Benedict, F. G., and Carpenter, T. M. Food Ingestion and Energy Transformation, Carnegie Institute of Washington, 1918, Pub. No. 261,

42. Zuntz, N., and von Mering. Arch. f. die ges. Physiol., 1883, xxxii, 173.

43. Bernstein, S., and Falta, W. Deutsch. Arch. f. klin. Med., 1918, cxxv, 233.

44. Sanger, B. J., and Hun, E. G. Arch. Int. Med., 1922, xxx, 397.

45. Higgins, H. L. Amer. Jour. Physiol., 1916, xli, 258.

46. Bornstein, A., and Holm, K. Biochem. Zeitscht., 1922, cxxx, 209.

47. Bennett, T. I., and Dodds, E. C. Brit. Jour. Exp. Path., 1921, ii, 58.

48. Lusk, G. Medicine, 1922, i, 311.

49. Hiller, A., Linder, G. C., Lundsgaard, C., and Van Slyke, D. D. Jour. Exp. Med., 1924, xxxix, 931.

50. Cammidge, P. J., and Howard, H. A. H. New Views on Diabetes Mellitus, London, 1923.

51. Langfeldt, E. Jour. Biol. Chem., 1921, xlvi, 381, 391 and 403.

52. Shaffer, P. A. Physiol. Rev., 1923, iii, 394.

53. Harrop, G. A., and Benedict, E. M. Jour. Biol. Chem., 1924, lix, 683.

54. Marriott, W. McK., and Howland, J. Arch. Int. Med., 1916, xviii, 708.

55. To appear in a later publication.

56. Falta, W., and Richter-Quittner, M. Biochem. Zeitcht., 1919, c, 148; 1921, cxiv, 145.

57. Brinkman, R., and Davis, V. Biochem. Zeitscht., 1920, cv, 93.

58. Csáki, L. Wien. Arch. inn. Med., 1921, iii, 459.

59. Hagedorn, H. C. Biochem. Zeitscht., 1920, cvii, 248.

60. Ege, R. Biochem. Zeitscht., 1920, cvii, 246; 1920, cxi, 189; 1921, cxiv, 88.

61. Austin, J. H., Stillman, E., and Van Slyke, D. D. Jour. Biol. Chem., 1921, xlvi, 91. 